\title{
Effect of Media Sterilization Time on Penicillin G Production and Precursor Utilization in Batch Fermentation
} Kishore Kumar Gopalakrishnan and Swaminathan Detchanamurthy*

Research Scholar, Department of Chemical \& Process Engineering, University of Canterbury, New Zealand

\begin{abstract}
Benzyl Penicillin (Penicillin G) is a secondary metabolite (Antibiotic) derived from Penicillium chrysogenum. Batch fermentation is widely used in the production of Penicillin G in laboratory scale and as well as in Industrial scale. The fermentation media for the production is sterilised at $1210 \mathrm{C}$ for 30 minutes as a usual practise in both scales of production. In our present study the production media used to produce Penicillin $\mathrm{G}$ was sterilized at various time intervals and the change in penicillin production along with the level of precursors utilized by the $P$. chrysogenum were analysed. The change in sterilization time varied the proportion of fermentation media converted from complex to simple. Studies were carried out in both shake flask level and also in laboratory scale fermenter ( 3 litres) with media containing PAA (Phenyl acetic acid) as precursor. The fermentation media used in this study contained $\mathrm{K}_{2} \mathrm{SO}_{4}, \mathrm{KH}_{2} \mathrm{PO}_{4}$, $(\mathrm{NH} 4)_{2} \mathrm{SO}_{4}$, corn steep liquor $\left(\mathrm{N}_{2}\right.$ source), Lactose (Carbon source) and $\mathrm{CaCO}_{3}$. The steam batch sterilisation at 1210 $\mathrm{C}$ was attempted with different time intervals between 25 to 50 minutes with 5 minutes increment. It was observed that change in the sterilization time increased the Penicillin-G production by $30 \%$ upto 30 minute and only $6 \%$ upto 45 minute and then it started to drop. HPLC method was used to carry out quantitative analysis of the product Penicillin G and the precursor Phenyl acetic acid. The results further concluded that though the rise in the sterilization temperature increased the Penicillin G production rate, it was cost effective as more energy required to rise the sterilization temperature which in turn increased the cost of production of Penicillin G.
\end{abstract}

Keywords: Benzyl Penicillin; Penicillin G; Fermentation; Sterilization; Phenyl acetic acid

Abbreviations: LCSB: Lactose Corn Steep Broth; PAA: Phenyl Acetic Acid; POAA: Phenoxy Acetic Acid

\section{Introduction}

First and foremost important unit operation required for carrying out fermentation successfully is media sterilisation [1]. In the fermentation industry the vegetative inoculum was prepared in seed tank and then transferred to fermentation tank with sterilised media. Nutrient media sterilization is an important process made for maintaining pure culture during the fermentation process. Nutrient media can be sterilized by 1) heating 2) filtration 3) irradiation 4) sonic vibration and 5) exposure to chemical agents. Throughout the fermentation industry, heating using steam is widely used as a sterilization method, since it is reliable and easy to control [2].

Nutrient media sterilisation by autoclaving was primarily used for the eradication of indigenous microbes, another important change which can occurs on the nutrient media simultaneously due to autoclaving is change in nutrient composition. Nutrient media widely used for the fermentation is complex mixtures of amino acids, vitamins, proteins, lipids, carbohydrates, nucleotides, nucleosides and minerals. Autoclaving of the fermentation media can lead to change in the composition of the nutrients by various mechanisms such as hydrolysis, degradation, conjugation and the formation of insoluble salts such as magnesium or calcium salts of phosphate. These salts are essential for the growth of the microbes and the production of the secondary metabolites [3]. During the sterilisation process before fermentation, indigenous microbial population were destroyed. At the same time simultaneous chemical changes in media can also be expected [4].

Primary Metabolites are found in all plant cells. These include sugars (carbohydrates), fats, oils and proteins, which are involved in the fundamental biochemical reactions common to all life. Secondary metabolites are the organic compounds which are produced in biologi- cal systems. These secondary metabolites would not involve directly in growth or reproduction of the organism [5] but they are not formed without a reason.

In an industrial production of penicillin by fermentation, the yield is augmented by the addition of a precursor such as phenyl acetic acid (PAA) or phenoxyacetic acid [6]. In order to avoid toxic effects, the precursor must be added repeatedly in small amounts during the fermentation. The penicillin side chain precursors, phenylacetic acid (PAA) and phenoxyacetic acid (POAA) are aromatic protonophores which are transported across the plasma membrane by free diffusion [7].

Among the secondary metabolites produced, penicillin is the most commercial antibiotics over the last 50 years. The total world market for $\beta$-lactum antibiotics is estimated to be about 15 billion US\$. The $\beta$-lactum antibiotics are now accounted for over $65 \%$ of the world antibiotics market [8]. The mode of penicillin fermentation is fed batch. The precursor phenoxy acetic acid (POAA) is added to the fermenter throughout the process in order to avoid substrate inhibition. For the production of optimal antibiotic the fermentation parameters such as temperature, $\mathrm{pH}$, dissolved oxygen, carbon dioxide, sugar, precursor, ammonia, etc. are closely monitored and controlled by computer programs [9].

*Corresponding author: Swaminathan Detchanamurthy, Research Scholar, Department of Chemical \& Process Engineering,Universityof Canterbury, New Zealand, Tel: +64-21-1348491; E-mail: Swami_biochem@yahoo.co.uk

Received June 06, 2011; Accepted October 11, 2011; Published October 20 2011

Citation: Gopalakrishnan KK, Detchanamurthy S (2011) Effect of Media Sterilization Time on Penicillin G Production and Precursor Utilization in Batch Fermentation. J Bioprocess Biotechniq 1:105 doi: 10.4172/2155-9821.1000105

Copyright: (C) 2011 Gopalakrishnan KK, et al. This is an open-access article distributed under the terms of the Creative Commons Attribution License, which permits unrestricted use, distribution, and reproduction in any medium, provided the original author and source are credited. 
After the formulation of industrial fermentation media, it was sterilized for killing the total microorganisms present before the inoculation of the desired culture. Mostly in fermentation industry the steam sterilization method is used. Once media was autoclaved at 15 psi pressure for 15 minutes it was extended under streaming steam for continuous three days, which increases the hydrolysis of lactose and maltose to the greatest extend which makes maximum utilization of media by the microorganisms [10]. In steam sterilization the heating and cooling process-control to maintain steady temperature profiles is difficult. To avoid the risk of incomplete sterilization the "over kill" heating is frequently employed [11].

\section{Materials and Methods}

\section{Culture and chemicals}

The culture used in this study was penicillin-G producing Penicillium chrysogenum strain from SPIC pharmaceuticals division, kudikadu village, Cuddalore, India. The Penicillium chrysogenum spores were provided in the ampoules, to which $1 \mathrm{~mL}$ of sterile water is mixed in sterile condition. $0.1 \mathrm{~mL}$ of the dilution was plated to LCSB plate (Lactose Corn Steep Broth) and kept for incubation for about 13 to 15 days. One $\mathrm{mL}$ was taken from this and serial dilution is made up to $10^{-6}$. The colony selection was based on the following morphological characteristics 1) Green colour 2) 3-12 $\mathrm{mm}$ in diameter 3) Uniform sporulation 4) Circular slightly enlonged with raised centres and 5) White margin.

\section{F1 Suspension preparation}

The selected colony was diluted in $2 \mathrm{~mL}$ of sterile water, and then the suspension was added into a conical flask which contained $100 \mathrm{~g}$ of rice. It was kept for 13 days incubation at $25^{\circ} \mathrm{C}$ with 60 to $65 \%$ of relative humidity. To the above suspension, $200 \mathrm{~mL}$ of $0.05 \%$ Tween 60 was added and mixed. Then the strain was collected along with Tween 60 by rice sediment back. Tween 60 surfactant was used to separate spores from rice. The $100 \mathrm{~mL}$ of this suspension was taken as the $\mathrm{F}_{1}$.

\section{Viability test}

From $\mathrm{F}_{1}$ suspension one $\mathrm{mL}$ was taken and made serial dilutions till $10^{-6}$ in Tween 60 solution. It was plated in a viability count media and then incubated at $25^{\circ} \mathrm{C}$ for 5 days. Then colony count was made for analysing the activity of spores. The $\mathrm{F}_{1}$ suspension showed viability count of 1.5 to $2 \times 10^{8}$ cells $/ \mathrm{mL}$ was taken for $\mathrm{F}_{2}$ stage. The number of colonies present in the viability count plate with less than $1.5 \times 10^{8}$ cells/ $\mathrm{mL}$ was not taken into consideration and that stain was not taken to the $\mathrm{F}_{2}$ stage. Because the number of colonies in the viability count media plates will reflect the activity of that stain.

\section{Seed and fermentation medium}

The seed media used in this work contains cotton seed meal 10 (g/l); corn steep powder $20(\mathrm{~g} / \mathrm{l})$; sucrose $40(\mathrm{~g} / \mathrm{l})$; ammonium sulphate $2(\mathrm{~g} / \mathrm{l}) ; \mathrm{KH}_{2} \mathrm{PO}_{4} 0.5(\mathrm{~g} / \mathrm{l}) ; \mathrm{CaCO}_{3} 5(\mathrm{~g} / \mathrm{l}) ;(\mathrm{pH} 6.3)$ and sterilised at $121^{\circ} \mathrm{C}$ for $15 \mathrm{~min}$. The seed media was inoculated after autoclaving at $121^{\circ} \mathrm{C}$ for $15 \mathrm{~min}$ with $10 \mathrm{~mL}$ of inoculum which contained $9 \times 10^{5} \mathrm{~mL}$ of spores per $\mathrm{mL}$ and the culture was incubated in a rotary shaker at $250 \mathrm{C}$ and $230 \mathrm{rpm}$ for 54 hours. . Fermentation media contained the following nutrient composition: phenoxy acetic acid $10(\mathrm{~g} / \mathrm{l})$; potassium sulphate $5(\mathrm{~g} / \mathrm{l}) ; \mathrm{KH}_{2} \mathrm{PO}_{4} 1.5(\mathrm{~g} / \mathrm{l})$; ammonium sulphate $12(\mathrm{~g} / \mathrm{l})$; corn steep meal $27.5(\mathrm{~g} / \mathrm{l})$; lactose $120(\mathrm{~g} / \mathrm{l})$; calcium carbonate $10(\mathrm{~g} / \mathrm{l})$ and corn oil 10 $\mathrm{mL}$. The media $\mathrm{pH}$ was adjusted to 6.5 .

\section{Sterilization}

Vertical autoclaves employed for media sterilisation was stainless steel and which can withstand pressure up to 22 psi, equipped with temperature and pressure display (macro scientific works Pvt Ltd). The media flasks are plugged with cotton and covered with aluminium foil and sterilised as batches at various time intervals of $25,30,35,40,45,50$ and $55 \mathrm{~min}$ at constant pressure of $22 \mathrm{psi}$.

\section{Inoculation and fermentation}

Sterilised media ( $\mathrm{pH}$ 6.5) in 3 batch flasks was inoculated with $3 \mathrm{~mL}$ of inoculum under laminar air flow and kept in orbital shaking incubator (REMI Instruments) at $220 \mathrm{rpm}$ for 164 hours.

\section{Analytical measurements}

The samples from all 3 batch flasks were examined at $41^{\text {st }}, 82^{\text {nd }}, 123^{\text {rd }}$ and $164^{\text {th }}$ minutes for finding the level of activity of Penicillin G production using RP-HPLC (Shimadzu Corporation). The column used in the analysis was C18-Hypersil Octadodecyl Silane (length $25 \mathrm{~cm}$, diameter $0.46 \mathrm{~cm}$ ). The polar mobile phase was contained potassium dihydrogen orthophosphate and $45 \%$ of acetonitrile (80:20) at $\mathrm{pH} 4.6$. and flow rate was used at $1.4 \mathrm{~mL} / \mathrm{min}$. In the case of standard fermentation procedures methanol was used as the secondary mobile phase instead of acetonitrile (60:40). The detector used was UV detector. The detector was of fixed type and the Light source was a $\mathrm{D}_{2}$ (Deuterium) Lamp.

\section{Results and Discussion}

On penicillin fermentation the media will be sterilised at $121^{\circ} \mathrm{C}$ for $30 \mathrm{~min}$, but in our study the media was sterilised at $121^{\circ} \mathrm{C}$ for various intervals of time between 25 and 55 minutes and the analysis was done at various fermentation time intervals, 41, 82, 123 and 164 minutes, respectively. The analysis was included the detection of penicillin $G$ production and unutilization of precursor phenoxyaceticacid (POAA) in the media. The media sterilised at $121^{\circ} \mathrm{C}$ for 45 minutes has shown the maximum production of penicillin $\mathrm{G}$ and utilization of POAA at all times $(41,82,123$ and 164 minutes) of analysis. The analysis was carried out in HPLC and the elution peak for POAA is obtained around third minute and the elution peak for Penicillin G around fifteenth minute.

\section{$41^{\text {st }}$ minute analysis}

The 5 set of flask undergoing fermentation containing different times sterilised media were taken from shaker after 41 minutes and analysed the level of penicillin G activity in that and the amount of unutilized POAA present in that. The media sterilised for 45 minute shown Table 1 activity $9.63 \%$ more than the activity at $30 \mathrm{~min}$ (Usual sterilisation time). After $45 \mathrm{~min}$, prolonged sterilisation up to $55 \mathrm{~min}$ leads to drop in the activity. The activity shown by $55 \mathrm{~min}$ sterilised media was only $32.39 \%$ compared to the activity $45 \mathrm{~min}$ sterilised media fermentation. The residual precursor POAA content was more in 25 minute sterilised media, which decreased steadily still 45 minute sterilised media. The flasks sterilised above 45 minutes showed an increase in POAA accumulation. 45 minute sterilised media showed $98.3 \%$ POAA less accumulated while compared with the residual POAA present in fermentation at 55 minutes sterilised media Figure 1.

\section{$82^{\text {nd }}$ minute analysis}

The 5 set of flask undergoing fermentation containing different time sterilised media were taken from shaker after $82^{\text {nd }}$ minute and 


\begin{tabular}{|c|c|c|c|}
\hline S. No & $\begin{array}{c}\text { Media sterilisation } \\
\text { time (minutes) }\end{array}$ & $\begin{array}{c}\text { Penicillin activity } \\
(\mathbf{1} \boldsymbol{\mu} / \mathbf{m L})\end{array}$ & $\begin{array}{c}\text { Residual POAA } \\
(\mathbf{m g} / \mathbf{m L})\end{array}$ \\
\hline 1 & 25 & 1021 & 8.01 \\
\hline 2 & 30 & 1329 & 4.52 \\
\hline 3 & 35 & 1406 & 2.191 \\
\hline 4 & 40 & 1438 & 2.005 \\
\hline 5 & 45 & 1457 & 0.331 \\
\hline 6 & 50 & 911 & 10.04 \\
\hline 7 & 55 & 472 & 16.76 \\
\hline
\end{tabular}

Table 1: Penicillin activity and residual POAA content in various sterilization time intervals of 41 minute fermentation media.

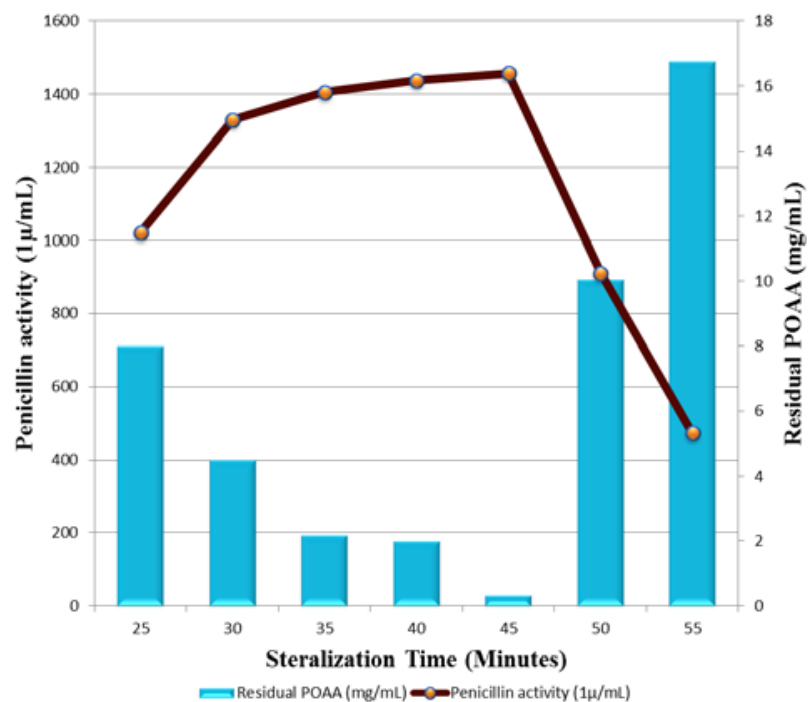

Figure 1: Penicillin activity and residual POAA content in various sterilization time intervals of 41 minute fermentation media.

analysed the level for penicillin activity in that and the amount of unutilized POAA present in that. The media sterilised for 45 minute showed Table 2 activity $14.16 \%$ more than the activity at 30 minute (Usual sterilisation time). After 45 minute of prolonged sterilisation up to 55 minute lead to drop in activity of penicillin G. The activity showed by 55 minute sterilised media was only $32.74 \%$ when compared to the activity 45 minute sterilised Media fermentation. The residual precursor POAA content was more in 25 minute sterilised, which decreased steadily till 45 minutes sterilised media. The flasks sterilised more than 45 minute showed increase in POAA accumulation. 45 minute sterilised media showed $87.24 \%$ POAA less accumulated while compared with the residual POAA present in fermentation 55 minutes sterilised media Figure 2.

\section{$123^{\text {rd }}$ minute analysis}

The 5 set of flask undergoing fermentation containing different time sterilised media were taken from shaker after $123^{\text {rd }}$ minutes and analysed for the level for penicillin activity in that and the amount of unutilized POAA present in that. The media sterilised for 45 minutes Table 3 showed activity of $5.332 \%$ more than the activity at 30 minute (Usual sterilisation time). After 45 minute of prolonged sterilisation up to 55 minute lead to drop in activity of penicillin G. The activity showed by 55 minute sterilised media was only $24.74 \%$ when compared to the activity 45 minute sterilised Media fermentation. The residual precursor POAA content was more in 25 minute sterilised, which decreased steadily till 45 minute sterilised media. The flasks sterilised more than

\begin{tabular}{|c|c|c|c|}
\hline S. No & $\begin{array}{c}\text { Media sterilisation } \\
\text { time (minutes) }\end{array}$ & $\begin{array}{c}\text { Penicillin activity } \\
(\mathbf{1} \boldsymbol{\mu} / \mathbf{m L})\end{array}$ & $\begin{array}{c}\text { Residual POAA } \\
(\mathbf{m g} / \mathbf{m L})\end{array}$ \\
\hline 1 & 25 & 10682 & 6.32 \\
\hline 2 & 30 & 14019 & 3.62 \\
\hline 3 & 35 & 14883 & 1.65 \\
\hline 4 & 40 & 15812 & 1.38 \\
\hline 5 & 45 & 16004 & 0.221 \\
\hline 6 & 50 & 9912 & 6.71 \\
\hline 7 & 55 & 5178 & 10.81 \\
\hline
\end{tabular}

Table 2: Penicillin activity and residual POAA content in various sterilization time intervals of 82 minutes fermentation media.

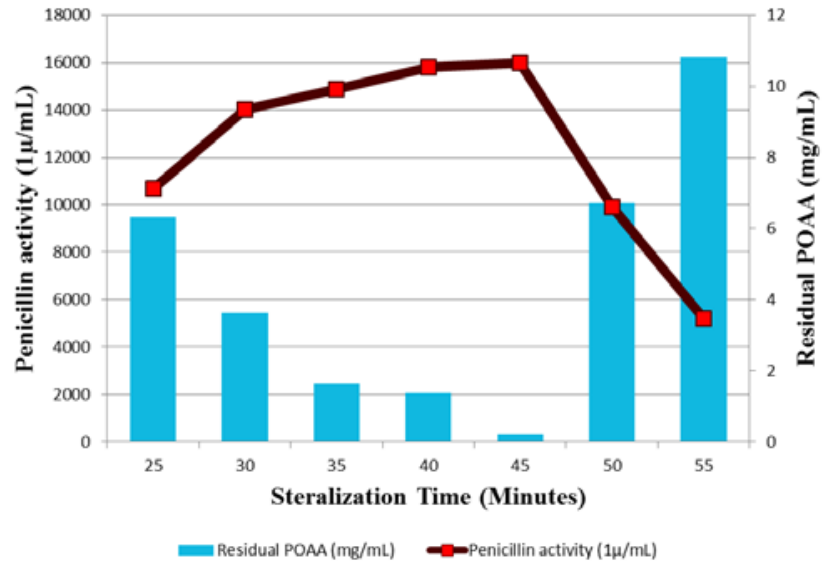

Figure 2: Penicillin activity and residual POAA content in various sterilization time intervals of 82 minute fermentation media.

\begin{tabular}{|c|c|c|c|}
\hline S. No & $\begin{array}{c}\text { Media sterilisation } \\
\text { time (minutes) }\end{array}$ & $\begin{array}{c}\text { Penicillin activity } \\
(\mathbf{1} \boldsymbol{\mu} / \mathbf{m L})\end{array}$ & $\begin{array}{c}\text { Residual POAA } \\
(\mathbf{m g} / \mathbf{m L})\end{array}$ \\
\hline 1 & 25 & 29081 & 5.213 \\
\hline 2 & 30 & 37791 & 2.91 \\
\hline 3 & 35 & 38934 & 1.33 \\
\hline 4 & 40 & 39195 & 1.1 \\
\hline 5 & 45 & 39806 & 0.171 \\
\hline 6 & 50 & 19861 & 5.15 \\
\hline 7 & 55 & 9851 & 8.12 \\
\hline
\end{tabular}

Table 3: Penicillin activity and residual POAA content in various sterilization time intervals of 123 minutes fermentation media.

45 minute showed increase in POAA accumulation. 45 minute sterilised media showed $97.89 \%$ POAA. Less accumulated while compared with the residual POAA present in fermentation 55 minutes sterilised media Figure 3.

\section{$164^{\text {th }}$ minute analysis}

The 5 set of flask undergoing fermentation containing different time sterilised media were taken from shaker after $164^{\text {th }}$ minutes and analysed the level for penicillin activity in that and the amount of unutilized POAA present in that. The media sterilised for 45 minute Table 4 showed activity of $8.315 \%$ which was more than the activity at $30 \mathrm{~min}$ ute (Usual sterilisation time). After 45 minute, prolonged sterilisation up to 55 minute lead to drop in activity. The activity showed by $55 \mathrm{~min}$ ute sterilised media was only $26.24 \%$ when compared to the activity of 45 minute sterilised fermentation media. The residual precursor POAA content was more in 25 minute sterilised, which decreased steadily till 45 minute sterilised media. The flasks sterilised more than 45 minute showed increase in POAA accumulation. 45 minute sterilised media 


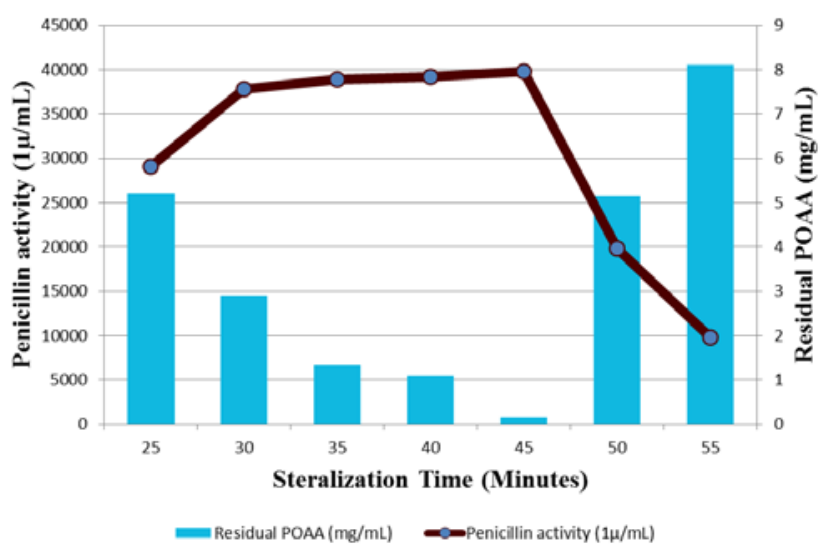

Figure 3: Penicillin activity and residual POAA content in various sterilization time intervals of 123 minute fermentation media.

\begin{tabular}{|c|c|c|c|}
\hline S. No & $\begin{array}{c}\text { Media sterilisation } \\
\text { time (minutes) }\end{array}$ & $\begin{array}{c}\text { Penicillin activity } \\
(\mathbf{1} \boldsymbol{\mu} / \mathbf{m L})\end{array}$ & $\begin{array}{c}\text { Residual POAA } \\
(\mathbf{m g} / \mathbf{m L})\end{array}$ \\
\hline 1 & 25 & 35071 & 4.21 \\
\hline 2 & 30 & 45291 & 2.32 \\
\hline 3 & 35 & 48195 & 1.05 \\
\hline 4 & 40 & 48954 & 0.91 \\
\hline 5 & 45 & 49057 & 0.14 \\
\hline 6 & 50 & 30672 & 4.02 \\
\hline 7 & 55 & 12876 & 6.21 \\
\hline
\end{tabular}

Table 4: Penicillin activity and residual POAA content in various sterilization time intervals of 164 minutes fermentation media.

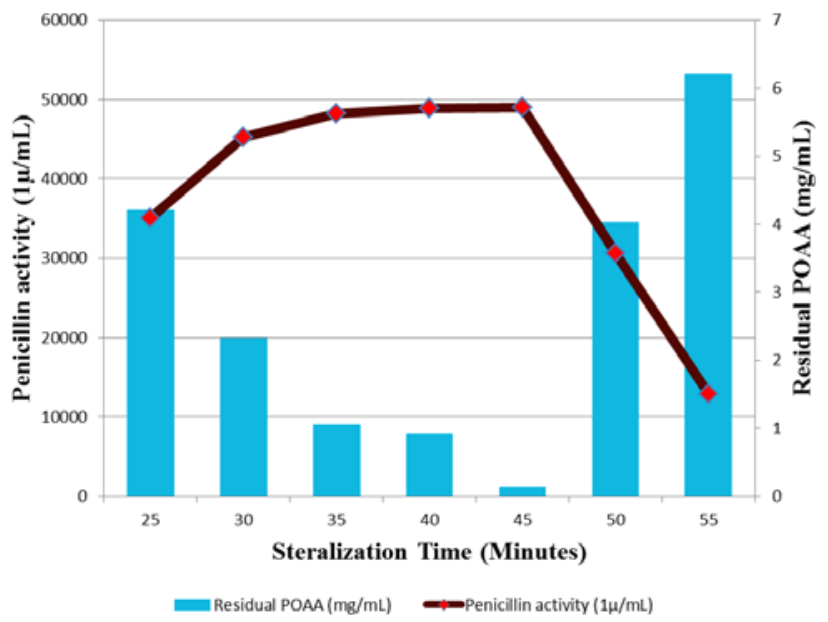

Figure 4: Penicillin activity and residual POAA content in various sterilization time intervals of 164 minute fermentation media.

show $97.74 \%$ POAA less accumulated while compared with the residual POAA present in fermentation 55 minutes sterilised media. The maximum Penicillin G fermentation is obtained in the 45 minutes sterilized media, whereas the media sterilised more than 45 minutes showed a decline in the Penicillin G fermentation Figure 4.

In order to maintain the unicellular fermentation, the media used should be free of microorganisms before inoculation of the Penicillium chrysogenum. Steam sterilisation is one of the best methods in sterilizing the fermentation media in industrial scale. The unknown benefit in sterilisation is making the media to be easily and maximum utilised by the microorganisms. The number and type of chemical reaction that can occur in fermentation media during heat sterilization are too complex for definition. The temperature and time profile of the sterilization process could theoretically affect the resulting component concentrations. Long sterilisation also has negative impact on the production on some cases; inhibitory products also can be produced or charring of the media which leads to decline the production of the fermentation product. The studies carried out by us proved that increasing the sterilization time has increased the Penicillin G production by $30 \%$ upto 30 minute and above 30 minute the increase in sterilization time didn't increase the Penicillin $G$ production much though there was a little increase. Moreover, it was observed that though the productivity of Penicillin $\mathrm{G}$ was increased as the effect of rise in Sterilization time, the cost involved in increasing the duration of sterilization was more than the cost of the product. Hence currently we are working on an alternative cheaper approach to increase the duration of sterilization without affecting the quality of the product and to get more profit from our Penicillin $\mathrm{G}$ production process.

\section{References}

1. Cooney CL (1985) Media sterilization. In: Cooney CL, Humphrey AE (eds) Per-gamon Press, London. pp. 209-211.

2. Deindoerfer FH (1957) Microbiological Process Discussion - Calculation of heat sterilization times for fermentation media. Applied microbiology 5: 221-228.

3. Doolin LE, Mertz FP (1973) The effect of inorganic phosphate on the biosynthe-sis of vancomycin. Can. J. Microbiol. 19: 263-270

4. Laverne Boeck D, Joseph Alford S, Jr Richard Pieper L, Floyd Huber M (1989) Interaction of media components during bioreactor sterilization: definition and importance of R0. J Industrial Microbiol 4: 247-252.

5. Fraenkel Gottfried S (1959) The raison d'Etre of secondary plant substances. Science 129: 1466-1470.

6. Eriksen SH, Jensen B, Schneider I, Kaasgaard S, Olsen J (1994) Utilization of side chain precursors for penicillin biosynthesis in a high-producing strain of Penicillium chrysogenum. Appl. Microbiol. Biotechnol. 40: 883-887.

7. Hillenga DJ, Versantvoort HJ, van der Molen S, Driessen AJM, Konings WN (1995) Penicillium chrysogenum takes up the penicillin G precursor phenylace-tic acid by passive diffusion. Appl. Environ. Microbiol 61: 2589-2595.

8. Elander RP (2003) Industrial production of b-lactam antibiotics. Appl. Microbiol. Biotechnol. 61: 385-392.

9. Rowlands RT (1991) Industrial strain improvement and the Panlabs penicillin club In: Kleinkauf $\mathrm{H}$, von Dohren $\mathrm{H}$ (eds) 50 years of penicillin applications: history and trends. Public, Czech Republic.

10. Mudge CS (1917) The effect of sterilization upon sugars in culture media. J. Bact. 2: 403-415.

11. Enzinger M, Goodsir S, Korozynski M, Parham F, Schneier M (1978) Validation of stream sterilization cycles Technical monograph No 1, Parentera Drug As-sociation, Inc., Philadelphia, USA.

12. Anderson TM, Bodie EA, Goodman N, Schwartz RD (1986) Inhibitory effect of autoclaving whey-based medium on propionic acid production by Propionibac-terium shermanii. Appl. Environ. Microbiol 51: 427-428. 